\title{
Morphology and Chemical Phenotype of the Ovarian Intrinsic Neurons in Neonate and Sexually Mature Reproductive Guinea Pig
}

\author{
Félix Luna ${ }^{1 *}$, Ericka Barrientos ${ }^{1}$, Victorino Alatriste1, Isabel Martínez ${ }^{1}$, \\ Ilhicamina D. Limón ${ }^{1}$, Oscar González-Flores ${ }^{2}$ \\ ${ }^{1}$ Departamento de Farmacia, FCQ-BUAP, Puebla, México \\ ${ }^{2}$ Centro de Investigación en Reproducción Animal, UAT-CINVESTAV, Tlaxcala, México \\ Email: felix.lunam@hotmail.com
}

Received 13 January 2015; accepted 3 February 2015; published 5 February 2015

Copyright @ 2015 by authors and Scientific Research Publishing Inc.

This work is licensed under the Creative Commons Attribution International License (CC BY). http://creativecommons.org/licenses/by/4.0/

\section{Open Access}

\section{Abstract}

Introduction: The existence of ovarian intrinsic neurons is well established. However, the morphology and chemical phenotype are not completely characterized and are even unknown for some species used in medical research. The purpose of this work was to determine the morphology and chemical phenotype of intrinsic neurons of the guinea pig ovary at two ages: neonates ( 0 days old) and sexually mature reproductive animals (90 days old). Materials and Methods: For the morphological analysis, we employed the modified Golgi-Cox impregnation technique. For the chemical phenotype, we used immunohistochemistry and the following antibodies; tyrosine hydroxylase (TH), calcitonin gene-related peptide (CGRP), transient receptor potential type 1 (TRPV1), neuron-specific nuclear protein ( $\mathrm{NeuN}$ ) and proto-oncogene product of the cFos gene (cFos). We also used enzyme histochemistry for NADPH-diaphorase detection. Results: The number of intrinsic neurons in the neonate ovary was low in comparison to the adult guinea pig ovary. The intrinsic neurons were located in the cortex and the ovarian medulla; some were isolated or clustered, forming ganglia, and others were interconnected and formed networks. The neurons were small, medium or large. In the cortex of neonate vs adult ovaries, the small and medium neurons comprised $23 \%$ vs $36 \%$ and $5.2 \%$ vs $11.6 \%$, respectively. In the medulla, the percent of the same neurons was $10.1 \%$ vs $10.1 \%$ and $1.1 \%$ vs $2.2 \%$ in the neonate and adult, respectively. In both cortex and medulla $<1 \%$ were large neurons at two ages. Also, the neurons were rounded, fusiform or multipolar. In the cortex, they were $12.7 \%$ vs $20.9 \%, 14.9 \%$ vs $24.2 \%$ and $1.1 \%$ vs $3.0 \%$, respectively. In the medulla, the percent of small vs medium neurons was $6 \%$ vs $7.1 \%$ and $4.1 \%$ vs $4.8 \%$ in the neonate and adult ovary, respectively, and $<1 \%$ were large neurons at both ages. The chemical phenotypes were in the neonate and adult: TH/NeuN-positive neurons, $16.3 \%$ vs $26.5 \%$; CGRP/NeuN, $13.5 \%$ vs $35.8 \%$; TRPV1/NeuN, $10.2 \%$ vs $38.6 \%$; and cFos/NeuN, $4.6 \%$ vs $5.4 \%$, re-

*Corresponding author. 
spectively. The percent of NADPHd-positive cells in the cortex was $9.5 \%$ vs $25.1 \%$ and $3.2 \%$ vs $62.2 \%$ in the medulla in the neonate and adult, respectively. Conclusion: Altogether, these data showed that the number of ovarian intrinsic neurons was low at birth and increased in the sexually mature reproductive guinea pig. The chemical phenotype was rich and peptidergic, catecholaminergic and nitrergic in nature and positive for cFos immunoreactivity. Therefore, intrinsic neurons can be chemical sensors inside of the gonad and transmit signal to the central nervous system.

Keywords

CGRP-, TRPV1-, TH-, NeuN-, cFos-, NADPHd-Positive Cells, Intrinsic Neurons, Guinea Pig Ovary

\section{Introduction}

It has been established that the mammalian ovary is supplied by sympathetic and sensory nerve fibers [1]-[3] and enclosed intrinsic neurons [4]-[8]. The sympathetic fibers predominantly release noradrenaline (NA) and vasoactive intestinal peptide (VIP), and the sensory fibers release peptides such as CGRP, substance P (SP) and galanin, among others [9]-[12]. Under physiological conditions, nerve fibers are involved in early follicular development and ovarian steroidogenesis [2] [13]-[15], i.e., NA stimulates androgen and progesterone secretion [16] [17], VIP stimulates estrogen production [18] [19] and CGRP and SP are involved in ovarian vascular fluid [9] [12]. Ovarian intrinsic neurons have been studied in several mammals (rats, monkeys and humans) [5] [7] and birds (hen and emu) [18] [19] and modulate steroidogenesis and local vascular fluid [2] [6] [14]. In the rat ovary, intrinsic neurons are located in the hilum and medulla of the ovary, first appear in the cortex during the juvenile period [5], and increase significantly during prepubertal development, reaching maximum values before puberty [6]. Using specific antibodies, neuronal cell bodies were recognized in the adult ovary of primates thatcontain the low-affinity receptor for nerve growth factor (NGFR), and some intrinsic neurons also tested positive for tyrosine hydroxylase, the rate-limiting enzyme in catecholamine synthesis [4]. In addition, the catecholaminergic nature of these neurons was demonstrated by the detection of mRNAs encoding both tyrosine hydroxylase (TH) and dopamine $\beta$-hydroxylase in the perikarya [6] [7]. Moreover, the peptidergic nature of these neurons were tested by immunohistochemistry and shown to be neuropeptide Y (NPY) positive [6]. Employing histological and histochemical criteria, isolated neurons and ganglia have been visualized in the ovary of prepubertal adult Wistar rats [5]; however, they were absent in the ovaries of Sprague-Dawley rats [6]. Despite these advances in ovarian intrinsic innervation, the information on these issues is incomplete and even unknown in several species frequently used in medical research. To increase the knowledge on this matter, the present study was designed to examine the distribution, morphology and chemical phenotype of the guinea pig ovarian intrinsic neurons at two ages: neonates ( 0 days old) and adult animals (90 days old).

\section{Materials and Methods}

\subsection{Animals and Samples}

During the experimental part of this study, we followed the principles of animal care approved by the BUAP Animal Care Committee and the national laws on animal protection (Mexican Council for Animal Care, Norma Oficial Mexicana NOM-062-ZOO-1999). The local guidelines were also in accordance with the National Institutes of Health Guide for the Care and Use of Laboratory Animals of the USA. All efforts were made to minimize animal suffering and to reduce the number of animals used. The immature guinea pigs (Caviaporcellus) were obtained at birth from pregnant animals. The adult guinea pigs were housed in groups ( 3 animals per cage) under a dark-light cycle of $12-12$ hours with a room temperature of $22 \pm 2$ degrees Celsius. Additionally, the animals had free access to food and potable water, which was supplemented with Vitamin C. We used thirty female guinea pigs, fifteen immature animals (at birth day, $\mathrm{P} 0$ ) and another fifteen sexually mature reproductive animals (90 days old, P90), randomly divided by ages into six groups $(n=5)$. The animals of the first and second group (P0 or P90, respectively) were used for ovary collection and modified Golgi-Cox impregnation. The ovaries of the animals of the third and fourth group were used for immunocytochemistry and evaluation of the co-expres- 
sion of CGRP/NeuN-, TRPV1/NeuN-, TH/NeuN-, and cFos/NeuN-positive cells, and the ovaries of the animals of the fifth and sixth groups were used for enzyme histochemistry and evaluation of NADPHd-positive cells. All experimental guinea pigs were sacrificed with $\mathrm{CO}_{2}$.

\subsection{Morphological Evaluation of the Ovarian Intrinsic Neurons by the Golgi-Cox Impregnation Technique}

The ovaries were treated by the modified Golgi-Cox technique [20] [21]. Previously, we tested different impregnation protocols (data not shown here) and the best results were obtained when the impregnation time was six weeks in the dark and a room temperature of $22 \pm 2$ degree Celsius. During this time, the impregnation solution was replaced with a fresh solution every seven days. When the impregnation time was complete, the ovaries were immersed in a $30 \%$ sucrose solution for one week and kept in the dark at room temperature. After that, the ovaries were serially sectioned at a thickness of $30 \mu \mathrm{m}$ at a freezing temperature on a microtome Leica (VT1000). All sections were placed onto gelatin-coated glass slides and exposed to $\mathrm{NH}_{4} \mathrm{OH}$ and fixed with Kodak solution (Kodak Co., USA). Subsequently, the histological sections were treated with alcohol and xylene and mounted on microscope slides with synthetic resin. The slides were stored in the dark before visualization under light microscopy.

\subsection{Antibodies}

The following antibodies were used: rabbit polyclonal and mouse monoclonal anti-CGRP (Calcitonin GeneRelated Peptide, Life Science); mouse monoclonal anti-TRPV1 receptor (Transient Receptor Potential Vanilloid type 1, Millipore); anti-TH (Tyrosine Hydroxylase, Abcam); rabbit polyclonal anti-cFos (Santa Cruz Biotechnology); rabbit polyclonal anti-FOX3/NeuN (FOX3, Abcam); and secondary antibodies FITC (IgG-free from goat, Millipore) and Texas Red (IgG-free from goat, Millipore).

\subsection{Chemical Phenotype Evaluation of the Ovarian Intrinsic Neurons by Immunohistochemistry}

The animals from each experimental group were sacrificed with $\mathrm{CO}_{2}$ and perfused with intracardiac isotonic saline solution ( $\mathrm{NaCl}, 0.9 \%$ ) followed by paraformaldehyde (4\%) in PBS, pH 7.4 (PF-PBS solution). The ovaries were removed and post-fixed in PF-PBS solution, embedded in paraffin and sectioned with a Leica SM2010R microtome $(5 \mu \mathrm{m})$. The sections were treated with xylene and ethanol and washed with PBS solution. The sections were blocked with bovine albumin (IgG-free), treated with Triton X-100 and washed with PBS at 24 degrees Celsius. The samples were incubated with the anti-CGRP (1:500), anti-TRPV1 receptor (1:50), anti-TH (1:800), FOX3/NeuN (1:250) or cFos (1:500) antibody overnight at 4 degrees Celsius and then incubated with a secondary antibody (FITC) (IgG-free from goat; 1:250) or Texas Red (IgG-free from goat; 1:400) for 2 hours at room temperature. The specificity of the antibodies was confirmed in separate experiments with additional negative controls, including tissue sections incubated in the absence of primary antibody. All sections were mounted on microscope slides with mounting fluid (Millipore, USA) and observed under a Leica fluorescence microscope.

We analyzed ovary sections from five different animals with three repeat analyses for each gonad. The images were captured with a Leica-DFC325 camera, and the data were stored on the PC hardware. For five different ovaries, we counted the positive cells in 10 representative fields of each tissue section using the cell counter tool from NIH ImageJ software. From a qualitative point of view, the following three levels of fluorescence intensity were identified: light, medium and high. The cells were considered positive if they had a strong color signal and negative if they had a light or medium color signal. The final quality score was assessed using the software measure tool; the cells were positive when the measure was $\geq 50$ arbitrary units, and the cells were negative when the measure was $\leq 49$ arbitrary units.

\subsection{Identification of NADPH-d Ovarian Intrinsic Neurons by Enzyme Histochemistry}

For NADPH-d staining, whole mounts of the ovary serial sections $(30 \mu \mathrm{m})$ through five ovary segments from different animals were used. The samples were incubated for one hour at 37 degrees Celsius with $1 \mathrm{mg} / \mathrm{mL} \beta \mathrm{NA}$ DPH-d (Sigma-Aldrich, USA), $0.2 \mathrm{mg} / \mathrm{mL}$ nitro-blue tetrazolium chloride (Sigma-Aldrich, USA), and 0.5\% tri- 
ton X-100 PBS in $10 \mathrm{mM}$ malic acid. After incubation, the whole mounts were washed in $0.1 \mathrm{M} \mathrm{PBS}$, and the sections were mounted with synthetic resin and examined by light microscope (Zeiss, Germany). In each experiment and for negative controls, we used samples with the same protocol in the absence of the $\beta$ NADPH-d enzyme.

\subsection{Samples and the Assessment of the Number of Neurons in the Ovaries}

Given that the ovaries are different sizes because they were from animals at two different ages, immature (0 days old, P0) and sexual mature reproductive guinea pigs (90 days old, P90), we standardized the number of samples using 10 histological sections per ovary symmetrically distributed along the entire gonad. After that, the neuron bodies were identified using light microscopy in 5 fields for each histological section, and the images were captured with a Cannon S80, stored in PC hardware and analyzed with the software Zoom Browser program, EX.

\subsection{Statistical Analysis}

Data represent the number of neurons identified in 50 microscopy fields examined from 10 sections and 5 fields per section per ovary. All data are expressed as the mean and SEM and were compared using the Student t-test. A probability of less than $5 \%$ was considered significant.

\section{Results}

\subsection{Amount, Location and Cell Body Size of the Ovarian Intrinsic Neurons Recognized by Golgi-Cox Impregnation}

In neonate ovaries, the number of intrinsic neurons was low $(10 \pm 0.4)$ but increased $62 \%$ over neonates in sexually mature guinea pig ovaries $(16.1 \pm 0.5)$. These neurons were differentially distributed; in the cortex of the neonate ovary there were $7.7 \pm 0.5$ intrinsic neurons (28.9\%), and in the cortex of the adult ovary there were $12.9 \pm 0.4$ neurons $(48.5 \%)\left({ }^{*} \mathrm{p}<0.05\right.$, Student $\mathrm{T}$-test). In the medulla of the neonate, the number of neurons was $2.8 \pm 0.2(10.5 \%)$, and in medulla of the adult ovary there were $3.2 \pm 0.3$ neurons $(12.1 \%)$ which was not statically different from the neonate (Student t-test).

Using the size of the cell body, the ovarian intrinsic neurons were classified as small [7 - $15 \mu \mathrm{m}(33.1 \%$ vs $46.3 \%$ for the neonate and adult, respectively)], medium [15 - $16 \mu \mathrm{m}(6.2 \%$ vs $13.6 \%$ for the neonate and adult, respectively)] or large [26 - $40 \mu \mathrm{m}<1 \%$ at both ages], located both in the cortex and in medulla of the ovary. In the ovarian cortex, the number of small neurons in the neonate ovary was $6.2(23 \%)$ and in the adult ovary the number was 9.7 (36\%), 0.6 times higher than the neonate ovary (Figure 1(A)) ( ${ }^{*} \mathrm{p}<0.05$, Student t-test). The number of medium neurons was $1.4(5.2 \%)$ and $3.1(11.6 \%)$ in the neonate and adult, respectively, and the number of large neurons was $<1 \%$ at both ages (Figure 1(A)), the number of neurons was not statistically significant (Figure 1(B)) (Student t-test). In the medulla of the ovaries, the number of neurons was similar in the neonate and adult: small neurons 2.7 (10.1\%) and 2.7 (10.1\%), respectively; medium neurons $0.3(1.1 \%)$ and 0.6 (2.2\%), respectively and the number of large neurons was $<1 \%$ at both ages. There was no statistical significance between any of these values (Figure 1(B)) (Student t-test).

By describing the morphology of the cell body the ovarian neurons could be considered rounded, fusiform and multipolar (Figure 2(A)). The rounded and fusiform neurons exhibited two processes arising from opposite poles of the cell body, whereas multipolar neurons had a triangular or rounded cell body and multiple processes emerging from the cell body (Figure 2(A)). In the cortex of the neonate ovary, the number of rounded neurons was $3.4 \pm 0.6(12.7 \%)$, while in the adult ovary it was $5.6 \pm 0.5(20.9 \%), 0.6$ times higher than the neonate ovary (Figure 2(B)) $\left({ }^{*} \mathrm{p}<0.05\right.$, Student t-test). The number of fusiform neurons in the neonate and adult were $4.0 \pm$ $0.6(14.9 \%)$ and $6.5 \pm 0.8(24.2 \%)$, respectively; fusiform neurons were 0.6 times higher in the adult than in the neonate ovary (Figure 2(B)) $\left({ }^{*} \mathrm{p}<0.05\right.$, Student-test). The number of multipolar neurons in the neonate and adult was $0.3 \pm 0.1(1.1 \%)$ and $0.8 \pm 0.2(3.0 \%)$, respectively, (Figure 1(B)) and no statistical significance was found between them (Student t-test). In the ovarian medulla and in comparison to the ovarian cortex, the number of neurons was lower and similar for the neonate and adult, rounded neurons $1.7(6 \%)$ and 1.9 (7.1\%), fusiform neurons, $1.1(4.1 \%)$ and $1.3(4.8 \%)$ and multipolar neurons $0.2(0.7 \%)$ and $0.05(0.2 \%)$, and no statistical significance was observed (Figure 2(B)) (Student t-test). 
Cortex

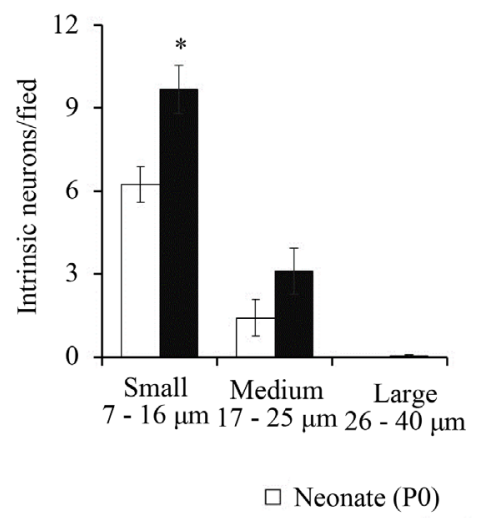

(A)
Medulla

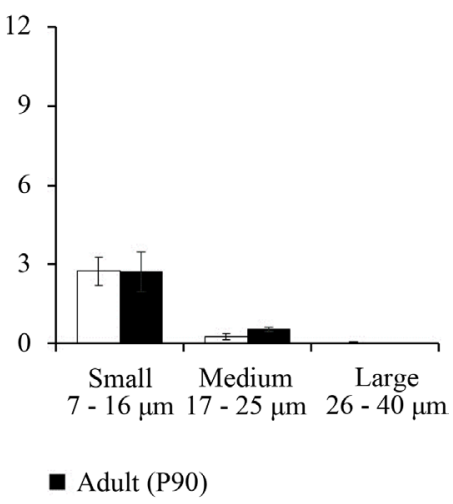

(B)

Figure 1. Distribution and cell body size of the intrinsic neurons in the guinea pig ovary. Graphic illustration of intrinsic neurons in the cortex (A) and medulla (B) of the neonate and adult ovary. The bars show mean and EEM, ${ }^{*} \mathrm{p}<0.05$, Student t-test.

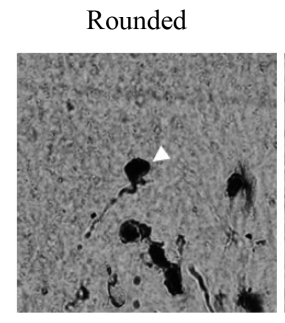

Cortex
Fusiform

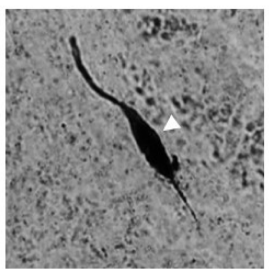

(A)

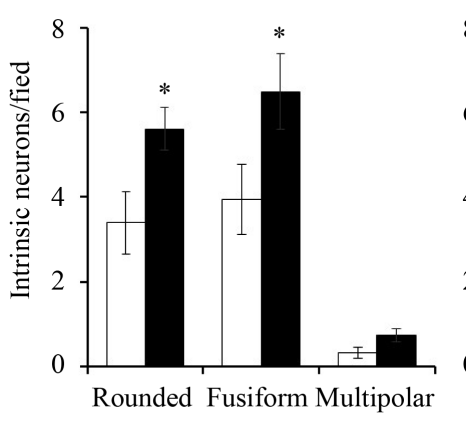

$\square$ Neonate (P0)

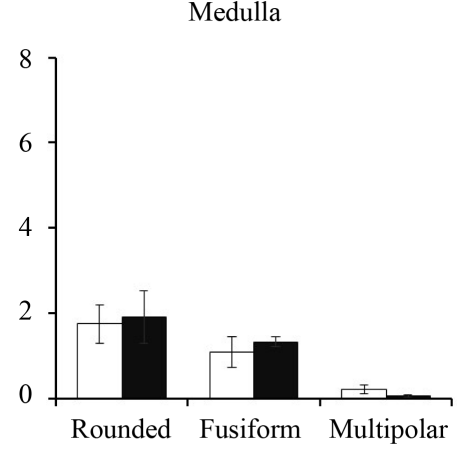

- Adult (P90)

(B)

Figure 2. Morphology and distribution of intrinsic neurons in the guinea pig ovary visualized by Golgi-Cox impregnation. Rounded, fusiform and multipolar intrinsic neurons (A). Graphic illustration of intrinsic neurons via the morphology of the cell body in the cortex and medulla of the neonate and adult ovary (B). The bars show mean and EEM, ${ }^{*} \mathrm{p}<$ 0.05 , Student t-test. Scale bar, $20 \mu \mathrm{m}$.

In general, we found that fusiform and rounded neurons were isolated while other neurons came together forming compact ganglia (Figures 3(A)-(D)). The multipolar neurons were persistently placed in the ovarian cortex, and this observation reached statistical significance (Figure 4(A)). In addition, we recognized nerve fibers close to neurons, follicles or blood vessels (data not shown here). 

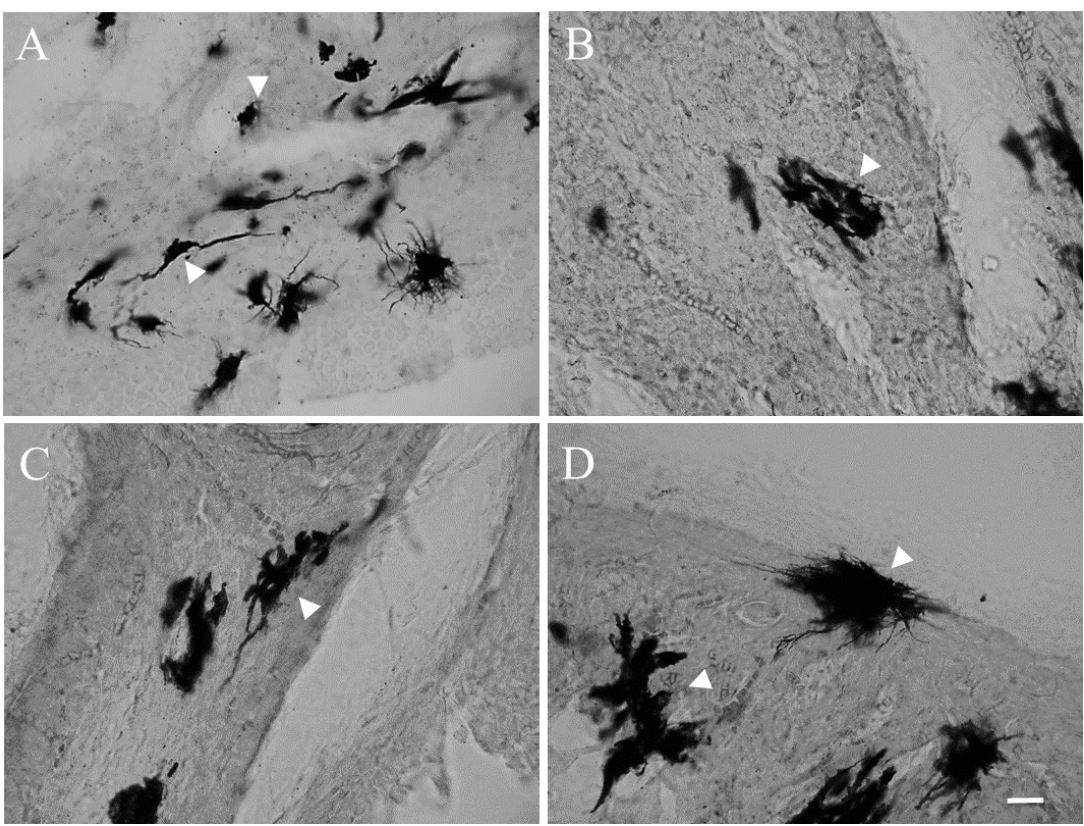

Figure 3. Neurons and ganglia in the adult guinea pig ovary visualized by Golgi-Cox impregnation. In the ganglia, the neurons had fusiform and rounded cell bodies. The neurons or ganglia are marked with arrowheads. Scale bar, $20 \mu \mathrm{m}$.
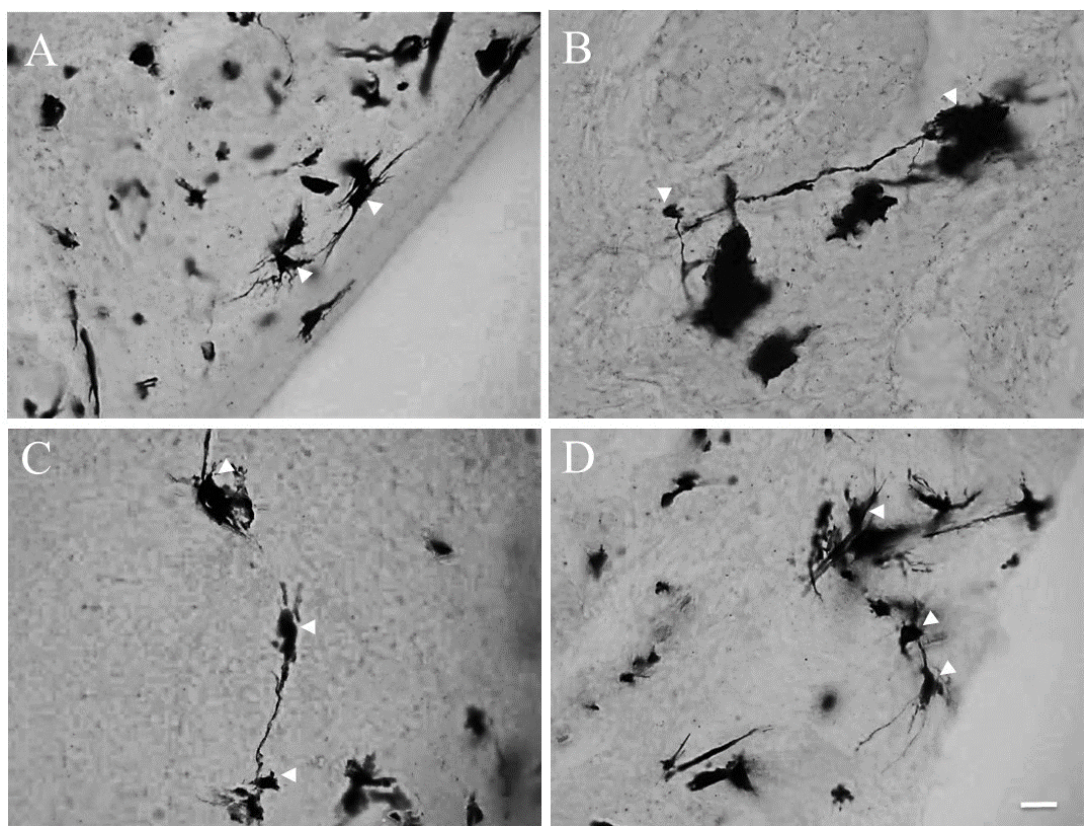

Figure 4. Neuron networks in the adult guinea pig ovary visualized by Golgi-Cox impregnation. The neuron networks were in the cortex and formed by bipolar or multipolar neurons. The cell bodies are marked with arrowheads. Scale bar, $20 \mu \mathrm{m}$.

\subsection{Ovarian Intrinsic Neuronal Networks}

Distinct from neurons in neonate ovaries, the adult guinea pig ovary had neurons making networks (Figure 4). The neuron networks were delimited to the cortex of the ovary and were structured by two neurons (Figures 4(A)-(B)), three neurons (Figure 4(C)) or several neurons (Figure 4(D)). The neuronal networks were primarily organized by multipolar cells. However, in some cases there were fusiform and rounded intrinsic neurons (Figure 4(C)). 


\subsection{Chemical Phenotype of the Ovarian Intrinsic Neurons}

\subsubsection{Tyrosine Hydroxylase Positive Cells (TH-Positive Cells)}

In the neonate ovary, the number of NeuN-positive cells, a specific marker for neurons, was 5.1 (23.7\%), and in the adult ovary there were 7.2 (33.5\%), 0.4 times higher than in the neonate ovary, whereas the number of neurons that co-expressed two neuronal markers (TH/NeuN-positive cells) was 3.5 (16.3\%) and 5.7 (26.5\%). In the adult ovary, the number of TH/NeuN-positive neurons increased 0.6 times in comparison to the neonate ovary and was statistically significant (Figures $5(\mathrm{~A})-(\mathrm{B}))\left({ }^{*} \mathrm{p}<0.05\right.$, Student t-test).

\subsubsection{Calcitonin Gene-Related Peptide Positive Cells (CGRP-Positive Cells)}

In the neonate ovary, the number of NeuN-positive cells was $4.6(14.1 \%)$, and in the adult guinea pig, it was 11.9 (36.6\%). Therefore, the number of neurons that co-expressed two cell markers (CGRP/NeuN-positive cells) were $4.4(13.5 \%)$ and $11.6(35.8 \%)$, respectively, numbers that show an increase in neurons 1.6 times in comparison to neonate ovaries (Figures 6(A)-(B)) $(\stackrel{*}{\mathrm{p}}<0.05$, Student-test).

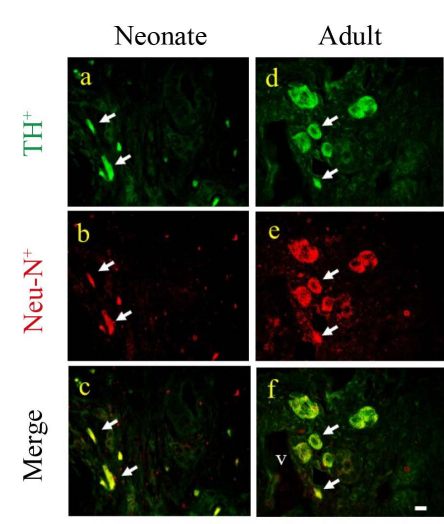

(A)

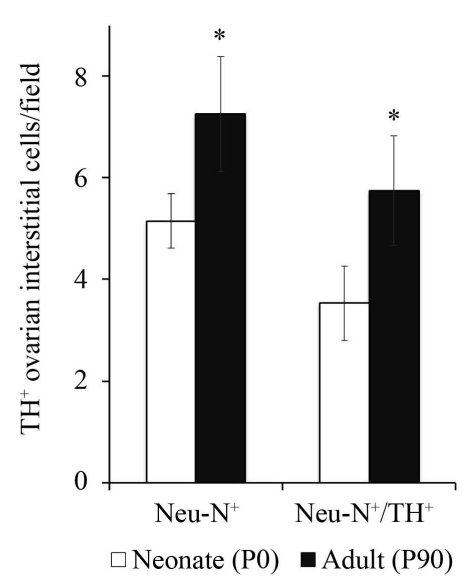

(B)

Figure 5. Immunohistochemistry of TH-positive neurons in the guinea pig ovary. The TH-positive neurons are in green marked with FITC for anti-TH ((A)a and (A)d), neuron bodies are in red, marked with Texas red and the monoclonal NeuN antibody (A(b) and $A(e)$ ) and merge ((A)c and A(f)), blood vessel (v). Graphic illustration of the number of intrinsic neurons in the neonate and adult guinea pig ovary (B). The bars show mean and EEM $(n=5),{ }^{*} \mathrm{p}<0.05$, Student t-test. Scale bar, $20 \mu \mathrm{m}$.

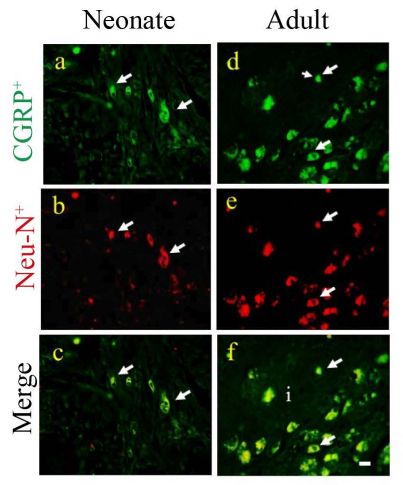

(A)

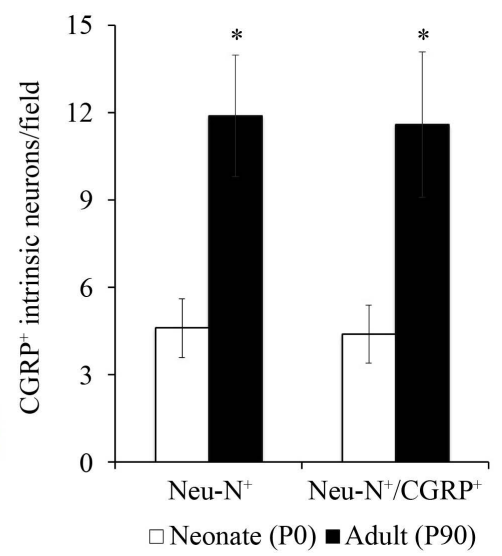

(B)

Figure 6. Immunohistochemistry of CGRP neurons in the guinea pig ovary. The CGRP-positive intrinsic neurons are in green marked with FITC for anti-CGRP ((A)a, A(d)), and the NeuN-positive neurons are in red marked with Texas red for the NeuN monoclonal antibody ((A)b, (A)d) and merge ((A)c, (A)f). Graphic illustration of the number of intrinsic neurons in the neonate and adult guinea pig ovary (B). The bars show mean and EEM $(n=5),{ }^{*} \mathrm{p}<0.05$, Student t-test. Scale bar, $20 \mu \mathrm{m}$. 


\subsubsection{Transient Receptor Potential Vanilloid Type 1-Positive Cells (TRPV1-Positive Cells)}

In both the neonate and adult guinea pig ovaries, the NeuN-positive cells were 5 (11.6\%) and 17.1 (39.6\%), respectively. The number of neurons that co-expressed two cell markers (TRPV/NeuN-positive cells) was 4.4 $(10.2 \%)$ in the neonate ovary and 16.7 (38.6\%) in the adult guinea pig. In the adult, the number of TRPV1/ NeuN-positive neurons increased 2.8 times in comparison to the neonate ovary (Figures $7(\mathrm{~A})-(\mathrm{B}))\left({ }^{*} \mathrm{p}<0.05\right.$, Student t-test).

\subsection{4. cFos Positive Cells}

In both the neonate and adult ovary, the number of cFos-positive cells was similar, with 32.1 (38.6\%) vs 33.6 (40.4\%) positive cells, respectively. However, the number of NeuN-positive cells was 4.1 (4.9\%) vs 5.1 (6.1\%). Finally, the number of cells that co-expressed the two cell markers (NeuN/cFos) was 3.8 (4.6\%) vs 4.5 (5.4\%). No statistical significance was observed for any of the cases (Figure 8(B)) (Student t-test).

\subsubsection{NADPHd Positive Cells}

Neonate as adult guinea pig ovaries had NADPHd-positive neurons (Figures 9(a)-(b)). In the cortex there were

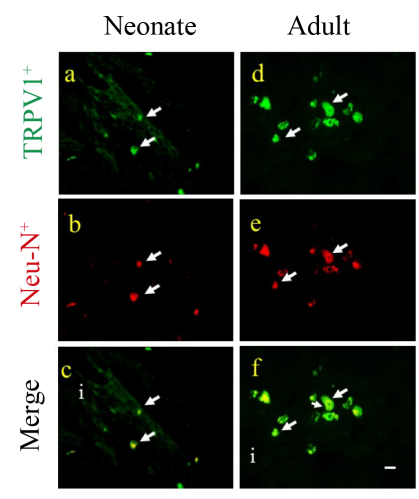

(A)

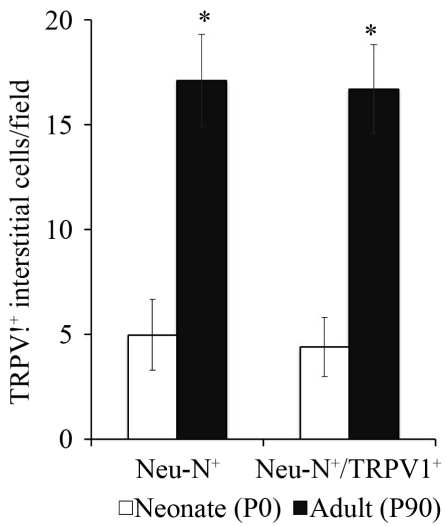

(B)

Figure 7. Immunohistochemistry of TRPV1-positive neurons in the guinea pig ovary. The TRPV1-positive intrinsic neurons are in green marked with FITC for the anti-TRPV1 receptor ((A)a and (A)d), and the NeuN-positive neurons are in red marked with Texas red for the NeuN monoclonal antibody ((A)b and (A)e) and merge ((A)c and (A)f). Graphic illustration of the number of ovarian intrinsic neurons $(B)$. The bars show mean and EEM $(n=5),{ }^{*} p<0.05$, Student t-test. Scale bar, $20 \mu \mathrm{m}$.

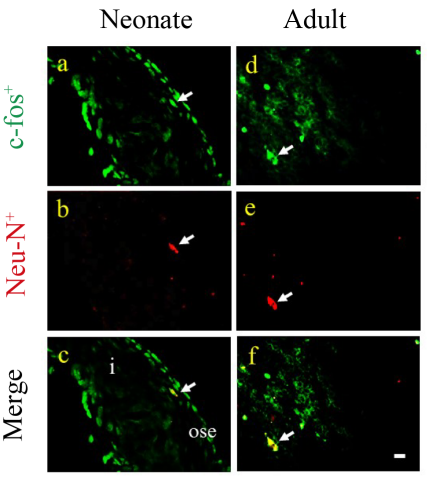

(A)

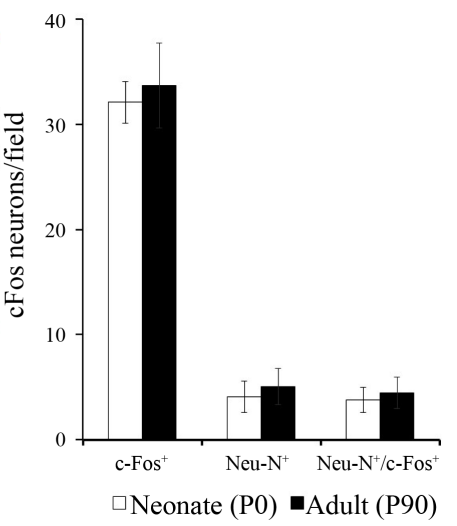

(B)

Figure 8. Immunohistochemistry for $\mathrm{cFos} / \mathrm{NeuN}$-positive cells $\left(\mathrm{cFos}^{+}\right)$in the guinea pig ovary. The cFos+ cells are in green marked with FITC for anti-cFos ((A)a, (A)c). NeuN-positive neurons are in red ((A)b, (A)d) and merge ((A)c, (A)f), ovarian surface epithelium, ose. Graphic illustration of the number of ovarian intrinsic neurons (B). The bars show mean and EEM (n= 5), ${ }^{*} \mathrm{p}<0.05$, Student t-test. Scale bar, $20 \mu \mathrm{m}$. 


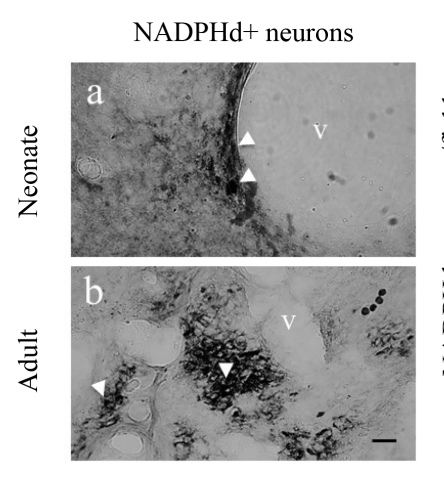

(A)

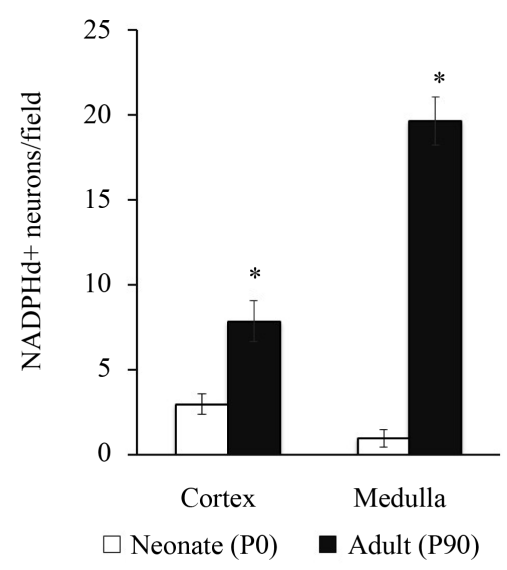

(B)

Figure 9. NADPHd labeled neurons in the guinea pig ovary. NADPHd positive neurons in the neonate (A)a and adult guinea pig ovary (A)b. Graphic illustration with the number of NADPHd neurons in the cortex and ovarian medulla (B). The bars show mean and EEM, ${ }^{*} \mathrm{p}<0.05$, Student t-test. Scale bars, $20 \mu \mathrm{m}$.

3.0 (9.5\%) and 7.9 (25.1\%) NADPHd-positive neurons for the neonate and adult, respectively, and in the medulla there was 1.0 (3.2\%) and 19.6 (62.2\%) positive cells, respectively (Figure 9(B)) ( ${ }^{*} \mathrm{p} \leq 0.5$ Student t-test).

\section{Discussion}

This is the first report to indicate the distribution, morphology and chemical phenotype of intrinsic neurons in the guinea pig ovary. The high number of neurons found in the adult ovary in comparison to the neonate ovary, and the higher amount in the cortex in comparison to the ovarian medulla adds to the information on ovarian intrinsic innervation in mammals. Additionally, these results are in concordance with other studies previously reported in rats [5] [6], monkeys and humans [7] [8] that reported ovarian intrinsic neurons increasing at sexual maturation [4] [8].

The small number of TH, CGRP and TRPV1 neurons in the neonate ovary (16.3\%, $13.5 \%$ and $13.5 \%$, respectively) that increased in the adult ovary (26.5\%, 35.8\% and 38.6\%, respectively) correlates with the high rate of steroidogenesis and high vascular blood fluid displayed in sexually mature reproductive ovaries [2] [3] [17]. In the primate ovary, catecholaminergic neurons are developed at the onset of puberty and are modulated by the ovarian hormones [4] [8]. Specifically, the long-term estradiol treatment of adult gilts down-regulates the population of noradrenergic neurons in the sympathetic chain gangliaprojecting to the ovary of adult pigs [22] [23]. Additionally, in cystic ovaries induced by dexamethasone, there are decreased CGRP and SP nerve fibers in the vicinity of the blood vessels in the gilt cystic ovaries [22]. Although controversial, another possibility is neurogenesis in situ. This is because, in vitro, a mixture of testosterone and progesterone after estradiol pretreatment converts the majority of ovarian epithelial cells of the porcine ovary into neural stem cells thereby differentiating them to neuronal cells [24] [25]. Also, ovarian stem cells show a high degree of plasticity and are able to differentiate into various types of somatic cells, including neural stem cells [24]-[26]. Ovarian stem cells express several markers recognized as pluripotent markers (SSEA-4, OCT4, SOX-2, among others) or multipotent markers (M-CAM/CD146, Thy-1/CD90, STRO-1, among others), which show support for the neural differentiation linage [26]-[28]. However, this hypothesis needs to be tested.

A novel result reported herein was the identification of multipolar neurons in the ovarian cortex, cells with several processes emerging from round or oval cell bodies. The multipolar ovarian neuron morphology was similar to Dogiel type II neurons described in the small intestine of several species [29]-[31], also called intrinsic primary afferent neurons [29] [30]. This comparison is supported by their chemical phenotype because guinea pig ovarian intrinsic neurons tested positive in response to TRPV1/NeuN antibodies, similar to Dogiel type II neurons that express TRPV1 receptors [32]. In these neurons, CB1 antagonists augment CGRP release via stimulation of the TRPV1 receptor and enhancement of the peristaltic reflex [32].

The neuron networks occur in the adult ovary and not in the immature ovary of the guinea pig, suggesting that they are developed along with the maturation of the reproductive system. In the sexually mature ovary, neuron 
molding is possible because long-term $17 \beta$-estradiol treatment reduces the population of neurons in the sympathetic chain ganglia connected to the ovary [33]. Furthermore, testosterone administration reduces the number of neurons in the caudal mesenteric ganglion innervating the ovary in sexually mature gilts [22] [23]. The high molding of the intrinsic neurons of the guinea pig ovary is supported by the widespread chemical phenotype expressed; TH/NeuN co-expression is indicative of catecholaminergic neurons [6] [8], CGRP/NeuN and TRPV1/ NeuN co-expression are markers for sensory neurons [34] [35] and NADPHd positivity is suggestive of nitrergic neurons and nitric oxide production [36] [37]. In addition, the fact that intrinsic neurons of the guinea pig ovary co-express cFos/NeuN proteins and cFos is a marker for early transcriptional activity [38] supports the notion that these neurons are functionally active. Moreover, TRPV1 and CGRP peptides are characteristic of sensory neurons that are abundant in pelvic organs. The CGRP neurons have two or more long processes emerging from an oval or round cell body, a characteristic of the intestine intrinsic primary afferent neuron [32] [39]. Therefore, the inhibition of the CGRP intrinsic sensory neurons modifies physiological actions [32].

The neuron networks and chemical phenotype of the intrinsic neurons in the guinea pig ovary suggest an integrative role. The presence of TH-positive neurons are in agreement with numerous networks formed by catecholaminergic neurons in the primate ovary, which are highly developed at puberty [4] and remodeled by local conditions such as hypoxia [40] [41]. Our results are the first to demonstrate that TRPV1-positive intrinsic neurons increase in population in the sexually mature reproductive guinea pig ovary. In sensory nerve fibers, the stimulation of the TRPV1 receptor induces CGRP release and vasodilation [42] [43], protecting the visceral tissues during ischemic processes [42]. The CGRP released from nerve perivascular terminals causes relaxation of the ovarian arteryin the sexually mature pig [44] and produces hypotension during pregnancy in ovariectomized rats treated with estradiol and progesterone [44]. In guinea pig ovaries, TRPV1/NeuN- and CGRP/NeuN-positive neurons were predominantly present in the interstitial compartment of the ovarian cortex, a site with a high number of follicles at a different stage of the development of sexually mature ovaries. Previously, it has been reported that CGRP immunoreactive nerve fibers were distributed in the medullar stroma in close contact with blood vessels [45]. In addition, in the guinea pig ovary, nitrergic neurons, identified by NADPHd positivity, are indicative of NOS production, and agree with previous results reported in rat ovaries [46] and monkeys [8]. In the guinea pig, NADPHd-positive neurons were more abundant in the medulla and less abundant in the cortex, suggesting regional differences in oxide nitric production. A differential distribution of NADPHd neurons has been reported in other reproductive organs, such as the urethra and penis of the rat, and is related to the different innervation pattern [47]; this is also the case in the rat dorsal root ganglia (L4) where the number of NADPHdpositive neuronsincreased after treatment of the LPS-treated sciatic nerve [48].

\section{Conclusion}

The ovary contained round, fusiform and multipolar-shape neurons, isolated or grouped in ganglia, making networks in the adult ovary. The neurons had profuse chemical phenotypes (CGRP/NeuN-, TRPV1/NeuN-, TH/ NeuN- and NADPHd-positive) and active considering its cFos immunoreactivity, supporting the notion that ovarian intrinsic neurons can be sensors in the gonad and transmit signals to the central nervous system.

\section{Acknowledgements}

This work was supported by VIEP-BUAP grants 2011-12, and Ericka Barrientos was supported by the Consejo Nacional de Ciencia y Tecnología through the postgraduate program (CONACYT/418053). Additionally, we are grateful to Diego Luna for his English language editing.

\section{Competing Interests}

The authors declare that they have no competing interests.

\section{Authors' Contributions}

All authors read and approved the final manuscript.

\section{References}

[1] Burden, H.W., Leonard, M., Smith, C.O. and Lawrence Jr., I.E. (1983) The Sensory Innervation of the Ovary: A 
Horseradish Peroxidase Study in the Rat. Anatomical Record, 207, 623-627.

http://www.ncbi.nlm.nih.gov/pubmed/6670757

http://dx.doi.org/10.1002/ar.1092070410

[2] Ojeda, S.R., Costa, M.E., Katz, K.H. and Hersh, L.B. (1985) Evidence for the Existence of Substance P in the Prepubertal Rat Ovary. I. Biochemical and Physiologic Studies. Biology of Reproduction, 33, 286-295. http://www.ncbi.nlm.nih.gov/pubmed/2412598

[3] Lara, H.E., McDonald, J.K. and Ojeda, S.R. (1990) Involvement of Nerve Growth Factor in Female Sexual Development. Endocrinology, 126, 364-375. http://www.ncbi.nlm.nih.gov/pubmed/2293994

[4] Dees, W.L., Hiney, J.K., Schultea, T.D., Mayerhofer, A., Danilchik, M., Dissen, G.A. and Ojeda, S.R. (1995) The Primate Ovary Contains a Population of Catecholaminergic Neuron-Like Cells Expressing Nerve Growth Factor Receptors. Endocrinology, 136, 5760-5768. http://www.ncbi.nlm.nih.gov/pubmed/7588334

[5] D’Albora, H. and Barcia, J.J. (1996) Intrinsic Neuronal Cell Bodies in the Rat Ovary. Neuroscience Letters, 205, 65-67. http://www.ncbi.nlm.nih.gov/pubmed/8867022 http://dx.doi.org/10.1016/0304-3940(96)12361-2

[6] D’Albora, H., Lombide, P. and Ojeda, S.R. (2000) Intrinsicneurons in the Rat Ovary: An Immunohistochemical Study. Cell and Tissue Research, 300, 47-56. http://www.ncbi.nlm.nih.gov/pubmed/10805074

[7] Anesetti, G., Lombide, P., D’Albora, H. and Ojeda, S.R. (2001) Intrinsicneurons in the Human Ovary. Cell and Tissue Research, 306, 231-237. http://www.ncbi.nlm.nih.gov/pubmed/11702234

[8] D’Albora, H., Anesetti, G., Lombide, P., Dees, W.L. and Ojeda, S.R. (2002) Intrinsicneurons in the Mammalian Ovary. Microscopy Research and Technique, 59, 484-489. http://www.ncbi.nlm.nih.gov/pubmed/12467023

[9] Dees, W.L., Ahmed, C.E. and Ojeda, S.R. (1986) Substance P- and Vasoactive Intestinal Peptide-Containing Fibers Reach the Ovary by Independent Routes. Endocrinology, 119, 638-641. http://www.ncbi.nlm.nih.gov/pubmed/2426085

[10] McDonald, J.K., Dees, W.L., Ahmed, C.E., Noe, B.D. and Ojeda, S.R. (1987) Biochemical and Immunocytochemical Characterization of Neuropeptide Y in the Immature Rat Ovary. Endocrinology, 120, 1703-1710. http://www.ncbi.nlm.nih.gov/pubmed/3552621

[11] Ricu, M., Paredes, A., Greiner, M., Ojeda, S.R. and Lara, H.E. (2008) Functional Development of the Ovarian Noradrenergic Innervation. Endocrinology, 149, 50-56. http://www.ncbi.nlm.nih.gov/pubmed/17947351 http://dx.doi.org/10.1210/en.2007-1204

[12] Kozłowska, A., Wojtkiewicz, J., Majewski, M. and Jana, B. (2011) Localization of Substance P, Calcitonin Gene Related Peptide and Galanin in the Nerve Fibers of Porcine Cystic Ovaries. Folia Histochemica et Cytobiologica, 49, 622-630. http://www.ncbi.nlm.nih.gov/pubmed/22252756 http://dx.doi.org/10.5603/FHC.2011.0085

[13] Aguado, L.I. and Ojeda, S.R. (1984) Ovarian Adrenergic Nerves Play a Role in Maintaining Preovulatory Steroid Secretion. Endocrinology, 114, 1944-1946. http://www.ncbi.nlm.nih.gov/pubmed/6538828 http://dx.doi.org/10.1210/endo-114-5-1944

[14] Mayerhofer, A., Dissen, G.A., Costa, M.E. and Ojeda, S.R. (1997) A Role for Neurotransmitters in Early Follicular Development: Induction of Functional Follicle-Stimulating Hormone Receptors in Newly Formed Follicles of the Rat Ovary. Endocrinology, 138, 3320-3329. http://www.ncbi.nlm.nih.gov/pubmed/9231784

[15] Luna, F., Cortés, M., Flores, M., Hernández, B., Trujillo, A. and Domínguez, R. (2003) The Effects of Superior Ovarian Nerve Sectioning on Ovulation in the Guinea Pig. Reproductive Biology and Endocrinology, 1, 61. http://www.ncbi.nlm.nih.gov/pubmed/14561223 http://dx.doi.org/10.1186/1477-7827-1-61

[16] Adashi, E.Y. and Hsueh, A.J. (1981) Stimulation of $\beta 2$-Adrenergic Responsiveness by Follicle-Stimulating Hormone in Rat Granulosa Cells in Vitro and in Vivo. Endocrinology, 108, 2170-2178. http://www.ncbi.nlm.nih.gov/pubmed/6112134 http://dx.doi.org/10.1210/endo-108-6-2170

[17] Dyer, C.A. and Erickson, G.F. (1985) Norepinephrine Amplifies Human Chorionic Gonadotropin-Stimulated Androgen Biosynthesis by Ovarian Theca-Interstitial Cells. Endocrinology, 116, 1645-1652. http://www.ncbi.nlm.nih.gov/pubmed/3971933 http://dx.doi.org/10.1210/endo-116-4-1645

[18] Madekurozwa, M.C. (2008) An Immunohistochemical Study of Ovarian Innervation in the Emu (Dromaius novaehollandiae). Onderstepoort Journal of Veterinary Research, 75, 59-65. http://www.ncbi.nlm.nih.gov/pubmed/18575065 http://dx.doi.org/10.4102/ojvr.v75i1.89

[19] Hofmann, P.G., Saldaña, A.B., Van Der Goes, T.F., González del Pliego, M. and Gutiérrez Ospina, G. (2013) Neuroendocrine Cells Are Present in the Domestic Fowl Ovary. Journal of Anatomy, 222, 170-177. 
http://dx.doi.org/10.1111/joa.12002

[20] Gibb, R. and Kolb, B. (1998) A Method for Vibratome Sectioning of Golgi-Cox Stained Whole Rat Brain. Journal of Neuroscience Methods, 79, 1-4. http://www.ncbi.nlm.nih.gov/pubmed/9531453 http://dx.doi.org/10.1016/S0165-0270(97)00163-5

[21] Gómez-Villalobos, M.J., Gordillo, A.C., López, J.R. and Flores, G. (2009) The Utility of the Golgi-Cox Method in the Morphological Characterization of the Autonomic Innervation in the Rat Heart. Journal of Neuroscience Methods, 179, 40-44. http://dx.doi.org/10.1016/j.jneumeth.2009.01.004

[22] Koszykowska, M., Całka, J., Gańko, M. and Jana, B. (2011) Long-Term Estradiol-17 $\beta$ Administration Reduces Population of Neurons in the Sympathetic Chain Ganglia Supplying the Ovary in Adult Gilts. Experimental and Molecular Pathology, 91, 353-361. http://dx.doi.org/10.1016/j.yexmp.2011.04.002

[23] Jana, B., Rytel, L., Czarzasta, J. and Całka, J. (2013) Reduction of the Number of Neurones in the Caudal Mesenteric Ganglion Innervating the Ovary in Sexually Mature Gilts Following Testosterone Administration. Journal of Neuroendocrinology, 25, 826-838. http://dx.doi.org/10.1111/jne.12057

[24] Bukovsky, A., Caudle, M.R. and Svetlikova, M. (2008) Steroid-Mediated Differentiation of Neural/Neuronal Cells from Epithelial Ovarian Precursors in Vitro. Cell Cycle, 7, 3577-3583. http://www.ncbi.nlm.nih.gov/pubmed/19001872 http://dx.doi.org/10.4161/cc.7.22.7101

[25] Stimpfel, M., Skutella, T., Cvjeticanin, B., Meznaric, M., Dovc, P., Novakovic, S., Cerkovnik, P., Vrtacnik-Bokal, E. and Virant-Klun, I. (2013) Isolation, Characterization and Differentiation of Cells Expressing Pluripotent/Multipotent Markers from Adult Human Ovaries. Cell and Tissue Research, 354, 593-607.

http://dx.doi.org/10.1007/s00441-013-1677-8

[26] Bukovsky, A. (2009) Sex Steroid-Mediated Reprogramming of Vascular Smooth Muscle Cells to Stem Cells and Neurons: Possible Utilization of Sex Steroid Combinations for Regenerative Treatment without Utilization of in Vitro Developed Stem Cells. Cell Cycle, 8, 4079-4084. http://www.ncbi.nlm.nih.gov/pubmed/19946214 http://dx.doi.org/10.4161/cc.8.24.10147

[27] Parte, S., Bhartiya, D., Telang, J., Daithankar, V., Salvi, V., Zaveri, K. and Hinduja, I. (2011) Detection, Characterization, and Spontaneous Differentiation in Vitro of Very Small Embryonic-Like Putative Stem Cells in Adult Mammalian Ovary. Stem Cells and Development, 20, 1451-1464. http://dx.doi.org/10.1089/scd.2010.0461

[28] Virant-Klun, I., Skutella, T., Stimpfel, M. and Sinkovec, J. (2011) Ovarian Surface Epithelium in Patients with Severe Ovarian Infertility: A Potential Source of Cells Expressing Markers of Pluripotent/Multipotent Stem Cells. Journal of Biomedicine and Biotechnology, 2011, Article ID: 381928. http://dx.doi.org/10.1155/2011/381928

[29] Bertrand, P.P., Kunze, W.A., Bornstein, J.C. and Furness, J.B. (1998) Electrical Mapping of the Projections of Intrinsic Primary Afferent Neurons to the Mucosa of the Guinea-Pig Small Intestine. Neurogastroenterology \& Motility, 10, 533-541. http://www.ncbi.nlm.nih.gov/pubmed/10050259 http://dx.doi.org/10.1046/j.1365-2982.1998.00128.x

[30] Hind, A., Migliori, M., Thacker, M., Staikopoulos, V., Nurgali, K., Chiocchetti, R. and Furness, J.B. (2005) Primary Afferent Neurons Intrinsic to the Guinea-Pig Intestine, Like Primary Afferent Neurons of Spinal and Cranial Sensory Ganglia, Bind the Lectin, IB4. Cell and Tissue Research, 321, 151-157.

http://www.ncbi.nlm.nih.gov/pubmed/15912404

http://dx.doi.org/10.1007/s00441-005-1129-1

[31] Chiocchetti, R., Bombardi, C., Mongardi-Fantaguzzi, C., Venturelli, E., Russo, D., Spadari, A., Montoneri, C., Romagnoli, N. and Grandis, A. (2009) Intrinsic Innervation of the Horse Ileum. Research in Veterinary Science, 87, 177185. http://dx.doi.org/10.1016/j.rvsc.2009.03.011

[32] Mitsui, R. (2010) Immunohistochemical Characteristics of Submucosal Dogiel Type II Neurons in Rat Colon. Cell and Tissue Research, 340, 257-265. http://dx.doi.org/10.1007/s00441-010-0954-z

[33] Grider, J.R., Mahavadi, S., Li, Y., Qiao, L.Y., Kuemmerle, J.F., Murthy, K.S. and Martin, B.R. (2009) Modulation of Motor and Sensory Pathways of the Peristaltic Reflex by Cannabinoids. American Journal of Physiology-Gastrointestinal and Liver Physiology, 297, G539-G549. http://dx.doi.org/10.1152/ajpgi.00064.2009

[34] Van Nassauw, L., Wu, M., De Jonge, F., Adriaensen, D. and Timmermans, J.P. (2005) Cytoplasmic, but Not Nuclear, Expression of the Neuronal Nuclei (NeuN) Antibody Is an Exclusive Feature of Dogiel Type II Neurons in the Guinea-Pig Gastrointestinal Tract. Histochemistry and Cell Biology, 124, 369-377.

http://www.ncbi.nlm.nih.gov/pubmed/16049694 http://dx.doi.org/10.1007/s00418-005-0019-7

[35] Price, T.J. and Flores, C.M. (2007) Critical Evaluation of the Colocalization between Calcitonin Gene-Related Peptide, Substance P, Transient Receptor Potential Vanilloid Subfamily Type 1 Immunoreactivities, and Isolectin B4 Binding in Primary Afferent Neurons of the Rat and Mouse. The Journal of Pain, 8, 263-272.

http://www.ncbi.nlm.nih.gov/pubmed/17113352 
http://dx.doi.org/10.1016/j.jpain.2006.09.005

[36] Grozdanovic, Z., Baumgarten, H.G. and Brüning, G. (1992) Histochemistry of NADPH-Diaphorase, a Marker for Neuronal Nitric Oxide Synthase, in the Peripheral Autonomic Nervous System of the Mouse. Neuroscience, 48, 225235. http://www.ncbi.nlm.nih.gov/pubmed/1374863 http://dx.doi.org/10.1016/0306-4522(92)90351-2

[37] Afework, M. and Burnstock, G. (1995) Colocalization of Neuropeptides and NADPH-Diaphorase in the Intra-Adrenal Neuronal Cell Bodies and Fibres of the Rat. Cell and Tissue Research, 280, 291-295. http://www.ncbi.nlm.nih.gov/pubmed/7781027 http://dx.doi.org/10.1007/BF00307801

[38] Chiu, R., Boyle, W.J., Meek, J., Smeal, T., Hunter, T. and Karin, M. (1988) The c-Fos Protein Interacts with c-Jun/ AP-1 to Stimulate Transcription of AP-1 Responsive Genes. Cell, 54, 541-552.

http://www.ncbi.nlm.nih.gov/pubmed/3135940 http://dx.doi.org/10.1016/0092-8674(88)90076-1

[39] Mitsui, R. (2011) Immunohistochemical Analysis of Substance P-Containing Neurons in Rat Small Intestine. Cell and Tissue Research, 343, 331-341. http://dx.doi.org/10.1007/s00441-010-1080-7

[40] Del Negro, C.A., Pace, R.W. and Hayes, J.A. (2008) What Role Do Pacemakers Play in the Generation of Respiratory Rhythm? Advances in Experimental Medicine and Biology, 605, 88-93. http://www.ncbi.nlm.nih.gov/pubmed/18085252 http://dx.doi.org/10.1007/978-0-387-73693-8_15

[41] Brouns, I., Van Genechten, J., Scheuermann, D.W., Timmermans, J.P. and Adriaensen, D. (2002) Neuroepithelial Bodies: A Morphologic Substrate for the Link between Neuronal Nitric Oxide and Sensitivity to Airway Hypoxia? The Journal of Comparative Neurology, 449, 343-354. http://www.ncbi.nlm.nih.gov/pubmed/12115670 http://dx.doi.org/10.1002/cne.10289

[42] Gazzieri, D., Trevisani, M., Tarantini, F., Bechi, P., Masotti, G., Gensini, G.F., Castellani, S., Marchionni, N., Geppetti, P. and Harrison, S. (2006) Ethanol Dilates Coronary Arteries and Increases Coronary Flow via Transient Receptor Potential Vanilloid 1 and Calcitonin Gene-Related Peptide. Cardiovascular Research, 70, 589-599. http://www.ncbi.nlm.nih.gov/pubmed/16579978 http://dx.doi.org/10.1016/j.cardiores.2006.02.027

[43] Luo, X.J., Liu, B., Dai, Z., Yang, Z.C. and Peng, J. (2013) Stimulation of Calcitonin Gene-Related Peptide Release through Targeting Capsaicin Receptor: A Potential Strategy for Gastric Mucosal Protection. Digestive Diseases and Sciences, 58, 320-325.

[44] Gangula, P.R., Zhao, H., Supowit, S., Wimalawansa, S., DiPette, D. and Yallampalli, C. (1999) Pregnancy and Steroid Hormones Enhance the Vasodilation Responses to CGRP in Rats. The American Journal of Physiology, 276, H284H288. http://www.ncbi.nlm.nih.gov/pubmed/9887042

[45] Häppölä, O. and Lakomy, M. (1989) Immunohistochemical Localization of Calcitonin Gene-Related Peptide and Bombesin/Gastrin-Releasing Peptide in Nerve Fibers of the Rat, Guinea Pig and Pig Female Genital Organs. Histochemistry, 92, 211-218. http://www.ncbi.nlm.nih.gov/pubmed/2674071 http://dx.doi.org/10.1007/BF00500920

[46] Jarrett, W.A., Price, G.T., Lynn, V.J. and Burden, H.W. (1994) NADPH-Diaphorase-Positive Neurons Innervating the Rat Ovary. Neuroscience Letters, 177, 47-49. http://www.ncbi.nlm.nih.gov/pubmed/7529906 http://dx.doi.org/10.1016/0304-3940(94)90041-8

[47] Vizzard, M.A., Erdman, S.L., Förstermann, U. and de Groat, W.C. (1994) Differential Distribution of Nitric Oxide Synthase in Neural Pathways to the Urogenital Organs (Urethra, Penis, Urinary Bladder) of the Rat. Brain Research, 646, 279-291. http://www.ncbi.nlm.nih.gov/pubmed/7520823 http://dx.doi.org/10.1016/0006-8993(94)90090-6

[48] Filogamo, G., Biasol, S., Recluta, E. and Vercelli, A. (2002) Increase in the Number of NADPH-Diaphorase-Positive Neurons in the Lumbar Dorsal Root Ganglia Following Lipopolysaccharide Exposure of the Sciatic Nerve. Morphologie, 86, 27-30. http://www.ncbi.nlm.nih.gov/pubmed/12224389 


\section{List of Abbreviations}

Calcitonin Gene Relate Peptide (CGRP);

Transient Receptor Potential Vanilloid Type 1 (TRPV1);

Tyrosine Hydroxylase (TH);

NADPH-Diaphorase (NADPHd);

Proto-Oncogene Product of the cFos Gene (cFos);

Neuron-Specific Nuclear Protein (NeuN). 
Scientific Research Publishing (SCIRP) is one of the largest Open Access journal publishers. It is currently publishing more than 200 open access, online, peer-reviewed journals covering a wide range of academic disciplines. SCIRP serves the worldwide academic communities and contributes to the progress and application of science with its publication.

Other selected journals from SCIRP are listed as below. Submit your manuscript to us via either submit@scirp.org or Online Submission Portal.
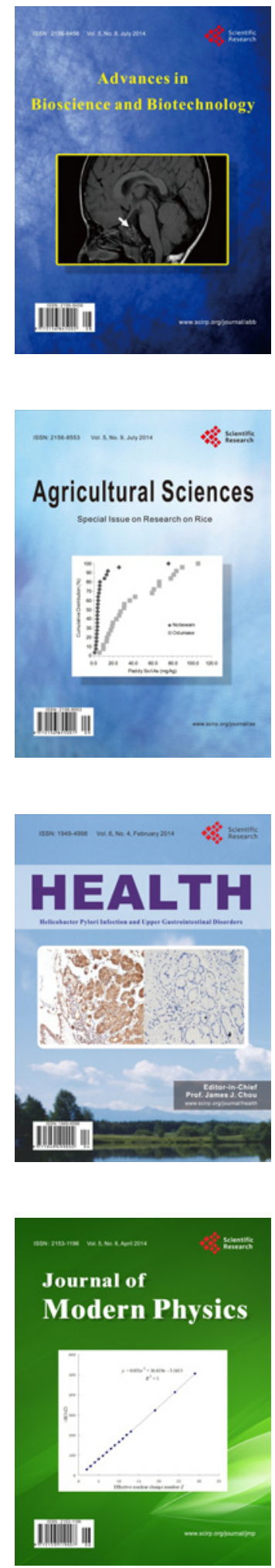
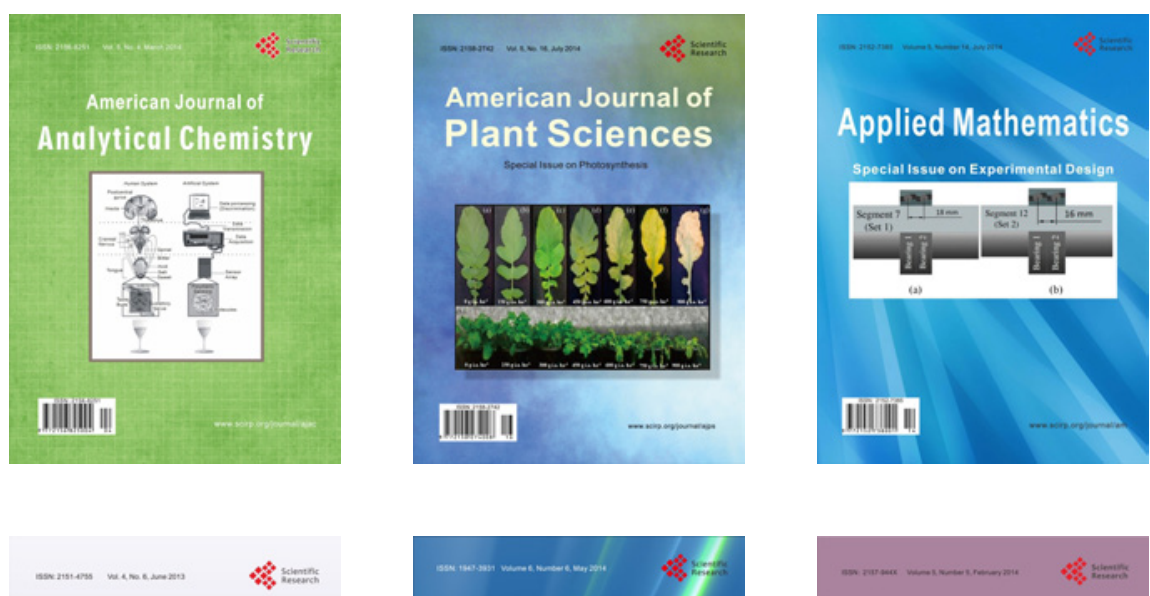

Creative Education
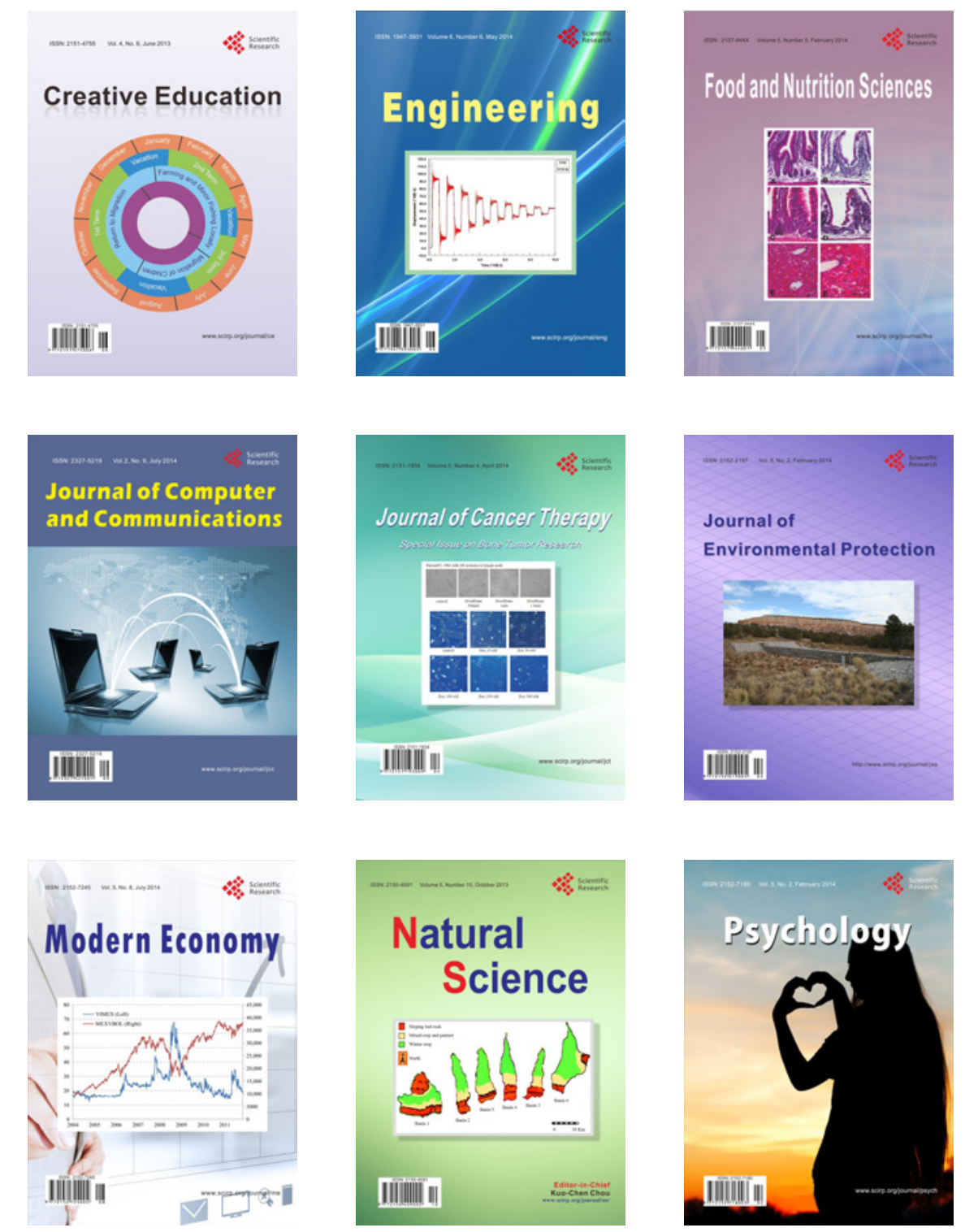